\title{
Comunidades ampliadas de pesquisa e ação no Movimento Antimanicomial
}

Enlarged Communities of Research and Action in the Anti-Asylum Movement

Patricia Tomimura ${ }^{1}$

RESUMO $O$ objetivo deste artigo é investigar a construção de um 'coletivo inteligente', patriciatomimura@gmail.com capaz de ações diretas e auto-organização, usando a metodologia da Comunidade Ampliada de Pesquisa e Ação (CAPA), como projeto-piloto, dentro do Núcleo de Luta do Movimento Antimanicomial do Rio de Janeiro, entre agosto e outubro de 2008. Apresentamos o resultado de três reuniões seguindo esse padrão. Concluímos que o projeto-piloto foi bem sucedido, pois os objetivos propostos foram atingidos parcialmente, mas seriam necessárias mais reuniões para atingi-los plenamente. Os participantes foram capazes de uma ação direta no encaminhamento das reuniões devido a uma organização tácita entre eles: o'coletivo inteligente' se mostrou possível.

PALAVRAS CHAVE: Projetos-Piloto; Metodologia; Reunião.

\begin{abstract}
The aim of this paper is to investigate the construction of an "intelligent collective", capable of direct action and self-organization, using the methodology of the Enlarged Community of Research and Action as a pilot project, within the Center for Fighting within the Anti-Asylum Movement of Rio de Janeiro, between August and October 2008. Here is the result of three meetings following this pattern. We conclude that the pilot project was successful since the goals were partially achieved, but more meetings would be needed to achieve them thoroughly. The participants were able of direct action in forwarding of the meetings due to a tacit organization among them: the "intelligent collective" proved possible.
\end{abstract}

KEYWORDS: Pilot project; methodology; meeting. 


\section{Introdução}

\section{Objetivo Geral}

O tema da pesquisa proposto é investigar a eficácia da construçáo de um coletivo inteligente dentro do Núcleo de Luta do Movimento Antimanicomial do Rio de Janeiro, entre agosto e outubro de 2008, no sentido de entender coletivamente como se dá o processo saúde/ loucura e seus modos de tratamento e cuidado na conjuntura política capitalista contemporânea. Com base nesse acúmulo teórico de discussóes, poderão ser avaliadas possíveis açóes diretas para combater o sofrimento psíquico.

Quanto à ação direta, ela é uma forma de ativismo anarquista que usa métodos mais imediatos para produzir mudanças desejáveis, ou seja, para atingir um fim planejado, mas não delegado a outrem, em oposição a meios indiretos, tais como a eleição de representantes políticos que prometem soluções para uma data posterior. A ação direta pode parecer um meio simples de resolver os problemas sociais, mas, na realidade, requer muito planejamento estratégico e de redes de apoio direto e indireto.

Seria necessário esclarecer o que são Coletivos Inteligentes e que metodologia foi usada para fazer encontros que propiciassem o alcance desse objetivo.

\section{Coletivos Inteligentes}

Para se entender o que seria a democracia em tempo real, sem representatividade, Pierre Levy descreve como isso funcionaria numa cidade ideal, a 'cidade inteligente': uma cidade que compreenderia avaliaçóes, decisões, expressôes, escuta molecular, visão emergente, conexôes e organização (LEVY, 1998, p. 70). Importa:

\section{(...) contribuir de maneira continua para a elaboração e o aperfeiçoamento dos problemas comuns, para a abertura de novas questóes, para a formulação de argumentos, para enun- ciar e adotar posiçôes independentes umas das outras sobre uma grande variedade de temas (...). A identidade política dos cidadãos seria definida por sua contribuição na construção de uma paisagem politica perpetuamente em}

movimento, e pelo apoio que dariam a determinados problemas (que eles julgarem prioritários), a determinadas posiçôes (as quais eles aderem), a determinados argumentos (que eles retomam por conta própria). Com isso, cada um teria uma identidade e um papel politico absolutamente singular e diferente de outro cidadão (...) criando diversidade, animando o pensamento coletivo. (LEVY, 1998, p. 65).

Nesse sentido, para uma utilização da democracia em tempo real - na qual Pierre Levy pressupóe o uso da internet -, em um grupo de discussão e produção de possíveis açôes na realidade atual, a dinâmica se daria da seguinte forma: uma questão é colocada por um membro do grupo, fruto de discussóes anteriores ou não. Logo em seguida, dão-se avaliaçôes por muitos outros membros e novas propostas. Cada um ouviria o outro a partir dos paradigmas desse outro e não dos seus próprios. Então, cada um tomaria uma decisão e comunicaria aos outros. Assim, novas avaliaçôes se dariam e, finalmente, uma decisão coletiva.

Piérre Levy enfatiza a importância de uma escuta molecular nos coletivos inteligentes. Ao expor sua vivência, cada sujeito precisa sair do lugar onde foi condicionado a funcionar, colocar-se de fora das representações que lhe foram engendradas, escutar outras representaçóes e significaçóes, e tentar fazer uma análise do discurso do outro.

\section{Metodologia}

\section{Marco teórico-metodológico}

A metodologia que eu pretendo utilizar articula-se com dois marcos teórico-epistemológicos, como as Comunidades Científicas Ampliadas, decorrentes do Modelo Operário Italiano, que, posteriormente, foi transformado para uso em escolas públicas do Brasil, em Comunidade Ampliada de Pesquisa que tinha o Dispositivo de Três Polos como forma de fomentar o diálogo.

Foi através de uma mesclagem dessas três abordagens que surgiu a Comunidade Ampliada de Pesquisa 
e Ação (CAPA), que utilizei para atingir meu objetivo explicitado no início deste trabalho.

\section{A Comunidade Científica Ampliada}

Mas como foi a construção histórica das Comunidades Científicas Ampliadas? No meio dos anos 1960, começou a se reunir um grupo de operários, cientistas, sindicalistas e estudantes, dentre os quais se encontrava Ivar Oddone. Nas primeiras pesquisas da área de saúde do trabalhador, a intervenção ainda era delegada aos especialistas, mas, posteriormente, o grupo começou a construir um novo modelo de conhecimento: o Modelo Operário, com uma intervenção sindical correspondente. Mas, do que se trata esse modelo?

Segundo Vicenti (1999), ele tem três eixos ou pilares: 1) o grupo operário homogêneo de produção; 2) a validação consensual; e 3) a não delegação.

1. O grupo operário homogêneo é o grupo de trabalhadores que vive a mesma experiência de trabalho como um conjunto.

2. A validação consensual é o que (e)leva os julgamentos qualitativos dos trabalhadores a se transformarem em critérios quantitativos de avaliação, alcançando o saber da experiência uma dimensão científica.

3. A não delegação é a não transferência da responsabilidade de análise e intervenção (referente às nocividades no trabalho) aos especialistas.

Para esta pesquisa, faz-se necessário integrar um diálogo crítico e fértil com essas diferentes vozes, com os pontos de vista e conceitos de diferentes disciplinas e com a experiência daqueles(as) que vivem a experiência da loucura e sabem de sua própria realidade, que têm um conhecimento da situação que é próprio de quem nela vive (mesmo que, muitas vezes, não saibam que sabem). A partir do diálogo crítico que acontece em tais encontros, podem-se compreender/transformar os processos que levam ao sofrimento patogênico e à doença e, então, encontrar os caminhos para a promoçáo da saúde desses usuários e técnicos (BRITO et al, 2003).

\section{Dispositivo de Três Polos}

Schwartz (2000) trata de três polos necessários para o diálogo entre diferentes segmentos, que podem ser aproveitados na CAPA.

O primeiro é o das disciplinas científicas. O segundo é o do saber da experiência. $\mathrm{O}$ terceiro polo, necessário para a fecundação dos outros dois, é o ético-epistemológico. Aqui se faz necessária uma 'humildade epistemológica', um sentir e ouvir o outro como legítimo outro. Há 'desconforto intelectual' porque os conceitos, pré-conceitos e o saber da experiência devem ser sempre tratados e retratados. Ocorre, então, um questionamento mútuo, que Schwartz (2000) chama de 'maiêutica em duplo sentido'.

As Comunidades Ampliadas de Pesquisa foram utilizadas no Brasil com a intenção de pôr em ação uma forma de investigação em parceria. $\mathrm{O}$ diálogo entre os polos capacita-os a reformular suas próprias questóes, suas formas de colocar as questóes, fortalecendo-os para recolocarem novas questôes (um para o outro) (BRITO et al, 2003).

Apesar da Comunidade Ampliada de Pesquisa ser também um processo de intervenção - porque sempre que a atividade se transforma em discurso, ela modifica a si mesma, pois o sujeito se modifica e modifica, assim, a ação -, mesmo assim, desejava-se enfatizar mais os aspectos da ação direta e da intervenção, necessários ao combate do sofrimento psíquico.

Dessa forma, esse projeto pode ser chamado de Comunidade Ampliada de Pesquisa e Ação (CAPA) porque o conhecimento tem que ter um uso ao interferir na realidade e na transformação social.

Nesse sentido, para a CAPA funcionar no Núcleo do Movimento de Luta Antimanicomial do Rio de Janeiro, integrando tanto técnicos (primeiro polo) quanto usuários e familiares (segundo polo), para fazê-los dialogar (terceiro polo), foi necessário criar encontros em que se pudesse avaliar se a presença do pesquisador seria potencialmente determinante na discussão e nas decisóes tomadas pelo grupo ou se o próprio grupo tomaria as rédeas da situação (não delegação). $\mathrm{O}$ grupo operário homogêneo e a validaçấo consensual não são mais relevantes pelas razóes a seguir: a primeira dizia respeito ao grupo de operários para quem as mudanças se dirigiam. 
$\mathrm{Na}$ CAPA, as mudanças e melhorias precisam se dirigir tanto aos técnicos (melhoria das condições de trabalho) quanto aos usuários (diminuir os dispositivos que lhes causam sofrimento psíquico). Nesse sentido, não pode haver um grupo homogêneo que misture técnicos e usuários, pois ambos vivem realidades muito diferentes. Quanto à validação consensual, o conhecimento produzido pelas Comunidades Ampliadas de Pesquisa já não precisava ter um status de ciência positivista, pois se entendia que esta não era a única forma válida de conhecimento para a mudança efetiva das condições de vida e de trabalho.

Além disso, seria também necessário verificar, a partir dos resultados percebidos nos encontros, se alguma açáo foi tomada ou planejada, o que seria um objetivo da pesquisa.

\section{Método}

$\mathrm{Na}$ prática, conseguiram-se realizar três encontros da CAPA: o primeiro em agosto, o segundo em setembro e o terceiro em outubro de 2008. Em média, participaram dez usuários, dois psicólogos, uma psiquiatra e nenhum familiar - todos membros do Núcleo do Movimento de Luta Antimanicomial do Rio de Janeiro. Esses encontros ocorreram na sede do Sindicato dos Médicos, na Rua Churchill, $94-11^{\circ}$ andar, Centro, Rio de Janeiro (RJ). Tiveram, em média, uma hora de duração cada. O primeiro e o terceiro encontros foram descritos por mim, na época, e o segundo foi gravado e transcrito. Todos os participantes assinaram listas de presença e, posteriormente (outubro de 2010), validaram um documento permitindo que suas falas fossem usadas para análise e feitura de artigo para publicação.

A estrutura dos encontros se deu da seguinte forma: a proposta de discussão foi distribuída por e-mail e na hora do encontro (uma a três laudas escritas). Em seguida, lia-se e discutia-se. Não foram feitas inscrições para as falas nem estipulados quantos minutos se poderia falar, mas quem queria falar levantava o braço. A coordenação do grupo coube a mim.

$\mathrm{Na}$ primeira reunião, o projeto acima (objetivo e embasamento teórico) foi discutido: conceitos de inteligência coletiva e dispositivo de três polos. $\mathrm{Na}$ segunda reunião, discutiu-se a questáo do normal ou da normalidade segundo Canguilhem (2006), pegando conceitos de seu livro "O normal e o patológico", especialmente dos capítulos "Norma e Média" e "Doença, Cura e Saúde". Foi feito um cartaz mostrando a eles a questão do normal, em termos de norma, quanto à origem da palavra, que se desdobra nos sentidos de média (como a média de açúcar no sangue) e de regra. Esse gráfico também continha uma seta mostrando um processo que vai da doença à saúde, passando pela normalidade. No terceiro encontro, discutimos o conceito de saúde, de Brito et al (apud ROCHA, 2001), no qual saúde está relacionada a uma série de aspectos mobilizados pelo cotidiano, para que a pessoa possa cumprir seu dever, e os acordos permanentes necessários para tornar a vida viável. Segue uma análise do discurso dos participantes dos encontros e as possíveis saídas para açóes diretas serem planejadas, além do surgimento do novo e do inesperado nos encontros.

\section{Análise dos Resultados}

\section{EIXO 1 - A validaçáo da proposta}

No primeiro encontro, a Dra M. coloca que todos os movimentos de luta antimanicomial, desde que surgiram, em Santo André (SP), surgiram espontaneamente, mas depois se organizaram e, por fim, se burocratizaram. Agora, o Núcleo de Luta Antimanicomial do Rio de Janeiro está voltando-se para a 'mesa redonda' (discutindo só questôes práticas de quem vai representar o quê, quando, que carta vai mandar para qual político etc.). O movimento encontra-se cristalizado e as pessoas, como ela e a familiar I., que já estâo na luta há mais de 20 anos, precisam de gás novo. Ela analisa que não é necessariamente bom romper com o movimento para criar algo novo, mas fazer o movimento crescer por dentro.

Dentro dessa narrativa e das falas subsequentes dos usuários e psicólogos, existe uma tentativa de se apropriar da proposta apresentada de ação direta e autogestão; existe um questionamento acerca de qual seria a melhor maneira do movimento proceder, tendo em 
vista tudo o que já se viveu em termos de relacionamento pessoal e institucional (do Núcleo) com as propostas da reforma psiquiátrica. Em suma, existe uma validação da proposta.

Usuário J. diz que, no início dos Centros de Atenção Psicossocial (CAPS), quando ele foi convidado a participar, tudo era feito e acordado junto, mas que agora ele só pode ir lá duas vezes por semana. Os outros dias ficam meio vazios para ele. Ele reivindica os Centros de Convivência e os Grupos de Mútua Ajuda remunerados. Foi colocado que essa não era a proposta.

Lemos juntos o projeto resumido, com interrupçóes para discussôes e questionamentos.

No final, a Dra $\mathrm{M}$. concordou que são necessárias açôes diretas para atrair 'sangue novo' para o movimento, acrescentando que açóes desse tipo já são feitas, como, por exemplo, a passeata do Teatro do Oprimido, no dia 18 de maio. Reconheceu que as reunióes do Núcleo estão apenas servindo para discutir os aspectos burocráticos, mas sugeriu que eu propusesse que toda segunda quarta-feira do mês nós nos reuníssemos no sindicato dos médicos para fazermos, inclusive, esse trabalho de construção de conhecimento coletivo, que também ajudaria os usuários a se colocarem de maneira mais eficiente, e que eu coordenaria esse grupo. Acrescentou que era necessário um núcleo que sustentasse a minha proposta.

Esse movimento do grupo, em especial, da $\mathrm{Dr}^{\mathrm{a}}$ $\mathrm{M}$, seria uma análise da oferta que estavam recebendo, ou seja, uma ponderação sobre se havia demanda contida nas propostas. Como foi considerado que havia necessidade desta, deu-se prosseguimento aos encontros.

\section{EIXO 2 - A questáo da transgressão}

No segundo encontro, o grupo entendeu a normalidade como um estado no qual não se cometem delitos, ao invés de focar a discussão no duplo sentido do termo norma (média e regra). Um usuário abordou o tema numa fala sobre o 'delito', que, consequentemente, foi muito discutido, inclusive pelos psicólogos, enquanto transgressão da regra.

Um usuário (J. B.) fez a seguinte colocação:
Existe $o$ ato, que seria a ação, e o desequilibrio emocional. Entre os dois, haveria a média (...). Você tem dois termos, dois caminhos a seguir. Você tem uma encruzilhada. Você tem o centro dessa encruzilhada para refletir o ato que você está cometendo. É o tempo de uma reflexão, que muitas vezes um erro náo se comete porque se pensa. (informação verbal) ${ }^{1}$.

Para o usuário, a média seria esse ato de reflexão cometido antes de você efetuar um delito. Nesse sentido, os usuários não veem os desvios de uma média como algo que possa promover saúde, como Canguilhem vê:

Mas será que devemos considerar qualquer
desvio como anormal? O modelo é, na reali-
dade, produto de uma estatística. Geralmente,
é o resultado de cálculos de médias. Porém, os
individuos reais que encontramos se afastam
mais ou menos desse modelo, e é precisamen-
te nisso que consiste a sua individualidade.
(CANGUILHEM, 2006, p. 110-111).

A Dra M., entretanto, traz a questão das regras - aquelas construídas e quebradas no interior do movimento, e a resistência das minorias às regras que lhes sáo opressoras no decorrer da história da democracia -, trazendo essa questão pela positividade e não pela negatividade. Os usuários e os psicólogos falam da regra pelo viés da normalizaçáo, como se esta constrangesse o indivíduo e fosse necessária sua transgressão, enquanto a Dra $\mathrm{M}$. abre para a reinvençáo do cotidiano no movimento, no sentido da normatização.

Pode ser, também, que os usuários e psicólogos, ao falarem de 'delito', estejam se referindo, de fato, a um acontecimento social. Ou seja, cometer um ato desviante da lei (ou em conflito com a lei) pode ser algo que foge à média. Nesse sentido, eles poderiam estar se referindo mais a relaçóes sociais do que à discussão de doença e saúde. Isso pode evocar uma discussão que Foucault (2006) trava na coleção 'Ditos e Escritos', v.

Fala do usuário J. B., em setembro de 2008, na segunda reunião da CAPA. 
IV, em que ele fala que o poder necessita da resistência para existir, assim como a resistência necessita do poder. Podemos concluir daí que, apesar dos binômios transgressão-normalidade e resistência-poder serem diferentes, ambos têm algo em comum: são termos que, simultaneamente, são máquinas de fluxos e máquinas de cortes, como diriam Deleuze e Guattari (1972).

Há um estranho desalinho entre a Dra M. e os demais participantes dessa discussão. Na sua primeira fala, ela coloca que todos ali presentes estão contra as regras, mas que a própria condição de se estar ali era que se haviam criado regras de participaçáo ${ }^{2}$. Ela enfatiza que as regras foram feitas pelos próprios participantes e que esses deveriam (a todo custo) obedecê-las. Assim, vemos que a Dra $\mathrm{M}$. faz um corte, uma resistência na discussão. Neste sentido, criamos um coletivo inteligente, com organização, conexóes, avaliações, decisões e escuta molecular. Isso é democracia em tempo real, como o colocaria Piérre Levy (1998).

\section{EIXO 3 - A questáo da cultura}

A questão da ação direta foi organizada mais como forma de questionamentos, que, desenvolvidos, poderiam gerar açôes organizadas para combater formas de sofrimento mental.

Uma proposta foi o questionamento do usuário A. quanto a fechar todos os hospitais que maltratassem os pacientes, em especial a Colônia Juliano Moreira, devido à proposta da reforma psiquiátrica. Para uma ação desse tipo ser organizada, seria necessário estudar mais sobre formas e história dos tratamentos em psiquiatria, para saber por que estávamos protestando e quais as formas alternativas de tratamento que poderíamos oferecer como substituição. Se aquela fosse a linha escolhida, teríamos, também, que acionar a mídia alternativa, os advogados populares e os deputados que atuam em apoio aos movimentos populares e sociais, para termos todo um backup e não construirmos uma ação direta isolada e sem efeito. Neste sentido, seria também necessário estudar quais técnicas (piquetes, projetos para a Câmara dos Deputados, passeatas) seriam utilizadas para causar maior efeito, que datas seriam mais eficazes, de que forma convocar o maior número de usuários, profissionais e familiares para ajudar/apoiar nos mais diversos modos etc.

Outra possibilidade de ação direta que apareceu foi um questionamento da Dra M. Ela coloca que os profissionais não sabem agir fora de seus papéis profissionais:

Os profissionais, eles podem ser rígidos e só saber trabalhar no hospital atrás de uma mesa, então, quando você propóe uma convivência num grupo musical, num teatro, eles não sabem como fazer. Ele só sabe ser médico naquele posto (...). $\mathrm{Na}$ hora de dançar, ele não sabe o que é a dança (...). Então, o importante nesse novo modelo de saúde mental é ter várias performances, porque permite que as pessoas mostrem aspectos positivos que atrás de uma mesa e uma cadeira não vai mostrar. E o médico, psicólogo passa a ser aquela pessoa perfeita, idealizada porque eles, em outras circunstâncias, vão ter uma performance pior que outros usuários. (informação verbal) ${ }^{3}$.

Uma ação direta que se desenha, neste caso, é de uma ação cultural que desmonta a própria ideologia de hierarquias e distâncias inatingíveis. Segundo nos diz Paulo Amarante, no congresso "As dobras da loucura", realizado na Fundação Oswaldo Cruz (FIOCRUZ), em dezembro de 2010:

Cultura é o conjunto de expressóes de um sujeito que não são apenas de sua personalidade individual, mas que são constituidas também pelas práticas sociais, coletivas. Essas expressóes não são só artísticas. Quando a gente fala cultura, não são só de hábitos, tradiçôes, rituais, de mitos, de formas de pensar, são tudo isso: são as formas de olhar o mundo, de interpretar, significar o mundo, de falar do mundo, de comer e de dançar, de pensar a religiāo. (informação verbal) ${ }^{4}$.

2Dra M.: "Então, por isso que a gente se organiza politicamente, pra construir regras que interessam a maior parte das pessoas".

${ }^{3}$ Fala da psiquiatra M., em setembro de 2008, na segunda reunião da CAPA.

${ }^{4}$ Entrevista gravada e depois transcrita. Fala de Paulo Amarante, no congresso "As dobras da loucura", em dezembro de 2010. 
A rigidez apontada pela $\mathrm{Dr}^{\mathrm{a}} \mathrm{M}$. náo termina no corpo dos técnicos, mas envolve tanto a instituição quanto os modos como esta instituição de tratamento está estruturada nos discursos que a perpassam. Neste sentido, parece-me que, quando o tratamento é voltado para tornar o paciente 'um artista', podem perderse de vista outras dimensóes culturais - a política, a pedagógica e a profissional. Já existe uma política de intersetorialidade na saúde mental, o que significa que setores como educação e geração de renda já estão sendo contemplados no tratamento de usuários enquanto propostas.

Nesse sentido de cultura, a relação entre o técnico e o usuário também está em jogo. A própria questão da transferência é questionada pela Dra M., que se pergunta se a idealização do médico e do psicólogo, numa transferência psicanalítica, num novo modelo de saúde, deve se dar numa base de relacionamento entre dois humanos, ambos em processo de se construir. As relaçóes entre seres humanos, seja no nível da clínica, seja da pesquisa, têm sempre de ser objeto de análise.

\section{Análise das implicaçóes - $\mathrm{O}$ chamado 'desvio de vivên- cia': como analisá-lo?}

No terceiro encontro, o usuário J. B. tomou a fala durante um longo período, ao discutirmos o conceito de saúde segundo Brito et al. Para mim, foi um misto de perturbação e inquietação com essa emergência do novo, pois sentia a necessidade de estar no controle da reuniāo e orientar, distribuir igualmente a fala entre os participantes e continuar a discussão do conceito acadêmico.

Entendi, depois, que o novo sempre aparece nas pesquisas com seres humanos e que é preciso abrir espaço para ele. Mirian Goldenberg coloca que nesse tipo de pesquisa há um envolvimento do pesquisador com o pesquisado, que pode influir no resultado da pesquisa, e que é preciso fazer uma análise de implicações para minimizá-lo ou incluí-lo como dado de pesquisa (GOLDENBERG, 1997, p. 55). No caso aqui citado, J. B. saiu do discurso acadêmico para fazer um passeio pelo jardim de sua própria vida, e eu o deixei falar, sentindo que, de alguma forma, ele falava pelo grupo: o grupo se auto-orientou sem a minha interferência.

\section{Conclusão}

Pelo EIXO 1, conclui-se que a ação direta como proposta de estratégia foi aceita pelo grupo. Pelo EIXO 2, conclui-se que há divisão nas opinióes quanto à questâo das regras sociais. Pelo EIXO 3, conclui-se que uma nova política de saúde mental é necessária, uma política que inclua a reforma psiquiátrica nas relações entre sociedade, usuários e técnicos (BRASIL, 2010)5.

Quanto aos princípios de não delegação, grupo homogêneo e validação consensual do Modelo Operário Italiano, podem-se tirar diferentes conclusôes de cada característica de tal modelo. Quanto ao princípio da não delegação, não coube aos técnicos que lá estavam presentes (psicólogos e uma psiquiatra), muito menos a mim, enquanto pesquisadora, dar a última palavra, e, sim, ao coletivo inteligente e diverso. Os usuários foram capazes de uma ação direta no encaminhamento da reunião devido a uma organização tácita entre eles. Então, vemos que a ação direta aconteceu de modo inusitado e que, mesmo que passeatas ou piquetes não tenham saído dali, uma organização do coletivo inteligente provou que foi capaz de surgir desta pesquisa. Houve açóes diretas em termos de auto-organização discursiva.

Entre os usuários, existe uma homogeneidade quanto ao fato de que todos já viveram a experiência da loucura e de que sáo rotulados e discriminados por isso. Porém, cada um vive a experiência da loucura de maneira muito singular. Os técnicos, por sua vez, mostraram opiniōes divergentes entre si, como na discussão sobre regras. Penso, portanto, que não existiu um grupo homogêneo, nem de técnicos nem de usuários, muito menos um único grupo homogêneo. Quanto à validação consensual, aqui não se aplica, pois, pela experiência que temos dos três primeiros encontros da CAPA, há divergência de opinióes entre os participantes.

${ }^{5}$ Os movimentos sociais, associações de familiares e usuários, e as organizações de técnicos convocaram, em 2010, a IV Conferência Nacional de Saúde Mental - Intersetorial, e, do seu relatório, (http://portal.saude.gov.br/portal/arquivos/pdf/2011_2_1 relatorio_IV.pdf) podemos extrair algumas propostas, como acontece no parágrafo 781 (referente à política indissociada da cultura), nos parágrafos 780, 793, 796, 798, 799 (referente à educação) e nos parágrafos 675 e 682 (referentes ao trabalho). 
A Comunidade Científica Ampliada e a Comunidade Ampliada de Pesquisa têm elementos que possibilitaram esta pesquisa, como, por exemplo, a não delegação e o dispositivo de três polos, além da possibilidade de se desenvolver açóes, respectivamente. Mas, se tomadas enquanto metodologias isoladas, náo provocariam o mesmo efeito nesse público. Isso ocorre porque somente alguns elementos se articulam com a questão da saúde mental e suas particularidades, como, por exemplo, a diversidade dentro de cada grupo estudado e a dificuldade de se chegar a um consenso em alguns assuntos.

Embora a CAPA tenha apresentado algumas limitaçóes, tais como ausência de familiares e de profissionais de outras áreas, ela mostrou-se uma metodologia capaz de estudar o sofrimento psíquico e de provocar açôes no público de saúde mental, atingindo os objetivos de formar um coletivo inteligente aonde houvesse discussões e a elaboração de estratégias de ação para combater o sofrimento mental. Embora a ação direta tenha se dado apenas dentro do grupo, na auto-organização e nas propostas, não havendo tempo para a efetivação destas, a utilização dessa metodologia em mais encontros certamente alcançaria os objetivos de forma mais intensa. Tal efetivação não se deu porque o sindicato no qual realizamos os encontros não nos disponibilizou a sala de reunióes por mais tempo. Porém, como se trata de uma pesquisa qualitativa, não é o número de encontros que garante a veracidade dos resultados, mas, sim, a intensidade de cada encontro.

\section{Referências}

BRASIL. Ministério da Saúde. Relatório da IV Conferência Nacional de Saúde Mental Intersetorial. 2011. Disponível em: <http://portal. saude.gov.br/portal/arquivos/pdf/2011_2_1relatorio_IV.pdf>. Acesso em 10 out 2011

BRITO, J. et al. Caderno de textos do Programa de Formação em Saúde, Gênero e Trabalho nas Escolas. João Pessoa: Universitária, 2003

CANGUILHEM, G. O Normal e o Patológico. 6. ed. Rio de Janeiro: Forense Universitária, 2006.

DELEUZE, G.; GUATTARI, F. OAnti-Édipo: capitalismo e esquizofrenia. São Paulo: Assírio e Alvim, 1972.

FOUCAULT, M. Poder e saber. In: Motta, M. B. (org.). Estratégia, poder-saber. 2. ed. Rio de Janeiro: Forense Universitária, 2006. p. 223-240. (Coleção Ditos \& Escritos, v. IV).
GOLDENBERG, M. A arte de pesquisar: como fazer pesquisa qualitativa em Ciências Sociais. Rio de Janeiro: Record, 1997.

LÉVY, P. A inteligência coletiva: por uma antropologia do ciberespaço, São Paulo: Loyola, 1998.

ROCHA, M. L. Educação e saúde: coletivização das ações e gestão participativa. In: Maciel, I. M. (org.). Psicologia e Educação: novos caminhos para a formação. Rio de Janeiro: Ciência Moderna, 2001. p. 213-229.

SCHWARTZ, Y. A comunidade científica ampliada e o regime de produção de saberes. Trabalho \& Educação, Belo Horizonte, n. 7, p. 38-47, jul./dez. 2000.

VICENTI, A. Ivar Oddone, intelectual orgánico e pesquisador heterodoxo. Les Territoires du Travail: les continents de l'experience, Cateis, n. 3, p. 33-42, maio 1999.

Recebido para publicação em Outubro/2011

Versão final em Junho/2012

Conflito de interesse: Não houve.

Suporte financeiro: Inexistente. 